\title{
The dark tetrad, social dominance orientation, and online political discussion
}

\section{Cory D. Taylor}

West Virginia University, cdt0023@mix.wvu.edu

Follow this and additional works at: https://researchrepository.wvu.edu/etd

Part of the Communication Technology and New Media Commons, Other Communication Commons, Other Political Science Commons, Other Psychology Commons, and the Social Media Commons

\section{Recommended Citation}

Taylor, Cory D., "The dark tetrad, social dominance orientation, and online political discussion" (2020). Graduate Theses, Dissertations, and Problem Reports. 7966.

https://researchrepository.wvu.edu/etd/7966

This Thesis is protected by copyright and/or related rights. It has been brought to you by the The Research Repository @ WVU with permission from the rights-holder(s). You are free to use this Thesis in any way that is permitted by the copyright and related rights legislation that applies to your use. For other uses you must obtain permission from the rights-holder(s) directly, unless additional rights are indicated by a Creative Commons license in the record and/ or on the work itself. This Thesis has been accepted for inclusion in WVU Graduate Theses, Dissertations, and Problem Reports collection by an authorized administrator of The Research Repository @ WVU. For more information, please contact researchrepository@mail.wvu.edu. 
The dark tetrad, social dominance orientation, and online political discussion

\title{
Cory David Taylor
}

\author{
Thesis submitted \\ to the Eberly College of Arts and Sciences \\ at West Virginia University \\ in partial fulfillment of the requirements for the degree of \\ Masters in \\ Communication Studies, Theory \& Research
}

\author{
Matthew M. Martin, Chair \\ Christine E. Rittenour \\ John G. Cole \\ Department of Communication Studies
}

Morgantown, West Virginia

2020

Keywords: dark tetrad, social dominance orientation, social media, trolling, American politics

Copyright 2020 Cory Taylor 


\begin{abstract}
The dark tetrad, social dominance orientation, and online political discussion
\end{abstract}

\title{
Cory Taylor
}

Previous literature into online trolling behavior has focused upon the role of the Dark Tetrad and political measures separately. This study extended the existing body of research by examining the relationship between the Dark Tetrad personality traits, social dominance orientation (SDO) and online political trolling in the United States of America. The data was collected using an online questionnaire from American users of Facebook and Reddit in the summer of 2020, during the COVID-19 pandemic, Black Lives Matter movement, and in the runup to a hotly contested national election. Positive correlations were found between all of the Dark Tetrad traits, SDO, with each other and trolling behavior. Regression analysis found positive correlations between Machiavellianism, psychopathy, and SDO with trolling behavior. These traits accounted for $55.9 \%$ of the variance in trolling behavior. 


\section{AKNOWLEDGEMENTS}

The author would like to thank his father, Richard C. Taylor, Ph.D., Marquette University \& Katholieke Universiteit Leuven; his step-mother Carolyn A. Taylor, Ph.D., Medical College of Wisconsin; and his dear friends: Margaret Burns, Caroline Drought, Andrew Jessen, Mitchell Keim, and Rachael E. Purtell for their support. 


\section{Table of contents:}

Cover Page: i

Abstract: ii

Acknowledgements: iii

1. Introduction: 1

2. Review of Literature: 2

2.1 The Dark Triad: 2

2.2 Social Dominance Orientation: 4

2.3 Trolling: 5

2.4 Online Political Discussion: 9

3. Hypotheses and Research Questions: 13

4. Methods: 14

4.1 Participants: 14

4.2 Procedures: 15

4.3 Measures: 17

5. Results: 18

6. Discussion: 21

6.1: Limitations: 26

6.2: Directions for Future Research: 27

7. Conclusion: 28

8. References: 29

Appendix A: Short Dark Triad-3.1.1: 35

Appendix B: Short Sadistic Impulse Scale: 37

Appendix C: Social Dominance Orientation-7: 38

Appendix D: Global Assessment of Internet Trolling-Revised: 39

Appendix E: Notable political affiliation opinion of participant: 39

Appendix F: Flowchart for trolling and dissemination of information on Twitter by QAnon conspiracy believers on 8Chan: 40 


\section{The dark tetrad, social dominance orientation, and online political discussion}

\section{Introduction}

The set of circumstances that the United States of America finds itself in are unprecedented in the history of the nation. An impeachment reaching trial on the eve of an election year is unique enough, then the entire world was hit with the worst pandemic in a century, and the largest social justice movement in a generation. That these events are the first of their kinds of the social media age is of historical importance to communication scholars. Unlike the last impeachment saga, a generation ago, it is now possible to go online and find ondemand discussion every hour of every day. Unlike the pandemic of 1918, a constant conversation is occurring online. Unlike the Civil Rights Era, persons on every side of the issues are able to directly interact through Facebook, Reddit, and Twitter, and other forums for perpetual political interactions, available wherever anyone has access to the internet.

With new forms of communication come new challenges. The rise of troll culture, within polarized political discussion in these unique times in the United States, creates an atmosphere of negativity. The reliance upon domestic trolls for foreign influence campaigns in political discourse, further heightens the need to study them. There is an opportunity present with high levels of political engagement amid the COVID-19 pandemic, social movements, and the 2020 United States elections to gain understanding that is currently lacking regarding the people in this phenomenon. This study investigated the relationship between the Dark Tetrad and online trolling as it applies to political discussion. 


\section{Review of Literature}

\subsection{The Dark Tetrad}

The Dark Tetrad is an extension of the original Dark Triad framework (Buckles, Jones, \& Paulhus, 2013). Paulhus and Williams (2002) identified of Machiavellianism, narcissism and psychopathy as "socially malevolent" personality traits, grouping them into the dark triad. These three traits are related, but independently measurable, and are antisocial in nature (Paulhus \& Williams, 2002). The majority of people with Dard Triad traits successfully navigate society, while acting in antisocial ways, due to the normalcy of people acting in socially destructive ways, while maintaining a degree of functionality (Paulhus \& Williams, 2002).

Machiavellianism, the name taken from Niccolò Machiavelli, and inspired by his writings, is defined as trait use of others as tools for attainment of one's goals in manipulative ways (Paulhus \& Williams, 2002). It is negatively related to the traits of agreeableness and contentiousness (Paulhus \& Williams, 2002). Subclinical narcissism as a trait manifests with an exaggerated love for self, need for recognition of one's perceived greatness and feelings of superiority to others; it is negatively related to agreeableness, and positively related to extraversion as well as openness (Paulhus \& Williams, 2002). Psychopathy, with desire for thrills, impulsive actions, and a lack of empathy was found to be positively related to extraversion and openness; while negatively related to agreeableness, conscientiousness, and neuroticism (Paulhus \& Williams, 2002).

The Dark Triad has been applied to the study of communication in a multitude of ways from interpersonal, in Horan, Guinn, and Banghart's (2012) study examining the Dark Triad's role in the conflict communication, to the role of the traits in toxic employee behaviors (Jonason, Slomski, \& Partyka, 2012). Dark Triad traits were found to correlate positively with contempt, 
criticism, stonewalling, and defensiveness, which are strong predictors of relationship termination (Horan, Guinn, \& Banghart, 2012). The traits, especially psychopathy, were also found to explain sex differences in employees where hard tactics were utilized in manipulation (Jonason, Slomski, \& Partyka, 2012).

Prejudice has been found to be linked to the Dark Triad in multiple cultures. The dark triad traits of Machiavellianism and psychopathy were found to positively correlate with racial prejudice and perceptions of intergroup threat among Canadian college students (Hodson, Hogg, \& MacInnis, 2009). In a study of Australian adults, all three traits were found to be positively related to racist views towards Middle Easterners by Anglo-Australians, but only psychopathy was found to be positively related to racist views towards Anglo-Australians by Middle Easterners (Jonason, 2014). Furthermore, while none of the traits were found to correlate with racist views by Anglo-Australians to their own group, psychopathy was again found to correlate positively with racist views by Middle Easterners to their own group (Jonason, 2014).

The Dard Triad has been found to be related to antisocial behavior online. Positive correlations between all three of the dark triad traits and problematic social media usage were found in a sample of Turkish college students (Kircaburun, Demetrovics, \& Tosuntas, 2018). Cyberbullying by American college students was found to be positively correlated with all three dark triad traits, with psychopathy being the strongest predictor of cyberbullying (Goodboy \& Martin, 2015).

In order to further understand traits role in antisocial behavior in 2013, Buckles, Jones and Paulhus added sadism to the Dark Triad, forming the Dark Tetrad. They argued that giving previous research showing not only that sadism was testable, but that it too positively predicted antisocial behavior, that its inclusion as a dark trait was warranted. Sadism, the desire for cruelty 
and the inflicting of pain on others, was found to correlate with the other dark triad traits, however it was unique enough that none fully explained it (Buckles et al., 2013). Sadists increase their attacks on innocent individuals when the victim does not defend themselves, and are unique among the dark traits in their willingness to devote work to hurting innocents. Among the dark traits, sadism is the most dangerous, and amoral (Buckles et al., 2013).

When applied to online antisocial behavior the study of sadism provided striking results. Sadism positively correlated stronger than any other dark trait with online trolling behavior in a study involving American adults and Canadian college students (Buckles, Trapnell, \& Paulhus, 2014). A further study found that among Canadian college students, participants with the sadistic trait gained pleasure from the perceived pain caused by trolling, as well as the act of trolling itself while the psychopathy trait only positively correlated with the latter (Buckles, Trapnell, Andjelovic, \& Paulhas, 2017). The negative social rewards gained through trolling itself is a possible motivating factor for those with the sadistic trait as well (Craker \& March, 2016). When the dark tetrad is applied to Facebook trolling specifically, it was found that Machiavellianism and narcissism were not positively related to trolling (Craker \& March, 2016). The researchers argued that Facebook may not be a satisfactory platform for Machiavellian trait individuals to manipulate others through without other trolling motivations, and that those high in trait narcissism gain no pleasure from the act of trolling itself, too involved with themselves to have interest in the act (Craker \& March, 2016).

\subsection{Social Dominance Orientation}

Social dominance orientation (SDO) is a testable personality trait that grew out of social dominance theory, the idea that social inequality comes from hierarchy-legitimizing myths that create a stratification within society (Pratto, Sidanius, Stallworth, \& Malle, 1994). Through the 
beliefs in these myths, SDO is strongly related to ethnic prejudice, sexism, nationalism, cultural elitism, gender stereotypes, economic conservativism, the noblesse oblige, and meritocracy. The trait can be used predictively independently in opposition to social programs, social justice and environmentalism (Pratto et al., 1994). Social dominance orientation as a trait is separate and distinct from trait authoritarianism, as it does not measure desire for power (Pratto et al., 1994).

People high in SDO tend to work in professions that maintain social hierarchy (Pratto, et al., 1994). Their beliefs that resources are finite, and groups compete for them with clear distinct winners and losers as a basis for our social system draws them to jobs enforcing this perceived order. Even those who do not hold jobs in such fields hold those who do in high esteem. While the majority of persons high in SDO perceive themselves to be in groups high in the hierarchy, those who are not in groups with high status tend to hold prejudice views against their own groups, or believe in a form of radical mobility for their group that would result in them oppressing others when their group gains supremacy (Pratto, et al., 1994).

Across cultures, men consistently score higher in social dominance orientation than women (Pratto et al., 2000). In studies of Canadian college students and Australian adults, Social dominance orientation was found to correlate positively with the dark triad traits (Hodson et al., 2009, Jonason, 2014). Sadism and Machiavellianism were found to be moderating factors on social dominance orientation in regards to college hazing, while all three traits predicted severe hazing activity (Arteta-Garcia, 2015).

\subsection{Trolling}

Understanding and defining online trolling behavior required new approaches. Hardaker (2010) noted that previous definitions created through the subfields of politeness research and computer mediated communication were insufficient to fully understand trolling. Instead of 
conceptualizing trolling as just an impolite, everyday antisocial act, it must be noted that it comes from a complex interaction between the sender, receiver, and the audience, whom may or may not be activated themselves as interactions continue (Hardaker, 2010).

Trolling is differentiated from cyberbullying in that trolling is aimed at a group or individual the troll does not personally know (Manuoğlu, 2020). Usually trolling is a singular event, while cyberbullying takes a targeted approach repeatedly attempting to cause injury (Manuoğlu, 2020). Both trolling and cyberbullying are instances of disregard for inhibitions in online interactions (Manuoğlu, 2020).

This study will use Hardaker's (2010) operant definition of trolling, "A troller is a CMC user who constructs the identity of sincerely wishing to be part of the group in question, including professing, or conveying pseudo-sincere intentions, but whose real intention(s) is/are to cause disruption and/or to trigger or exacerbate conflict for the purposes of their own amusement” (p. 237). According to Hardaker (2010), there are four distinct outcomes possible from trolling interactions:

A.) Frustrated: the troll is recognized by the recipients/audience and is ignored, thus denying them the desired response

B.) Thwarted: the troll is recognized, and the recipients/audience employ counter-trolling tactics, neutralizing the troll

C.) Fail: the troll is not recognized, but because of their inability to utilize their rhetoric in a meaningful way, does not elicit their desired response from the recipients/audience

D.) Success: the troll is not recognized, and does elicit the desired response from the recipients/audience. 
In order to attempt to gain a successful outcome, there are a variety of tactics that trolls engage in. Commonly utilized trolling techniques identified in trolling behavior are primarily deception, aggressive behavior intended to goad others into a desirable response by the troll, and disruptive tactics that while not aggressive directly employ nonsensical or farcical rhetoric as well (Hardaker, 2010). Fichman and Dainas (2019) further identified techniques of sarcastic seriousness or politeness, utilizing hyperbolic levels expected online behavior in ways that cause agitation in others, as well as the troll revealing themselves to the recipients/audience in a way that declares their success state before it has been attained in an effort to confound and annoy.

Trolls share many characteristics with the Batman villain "The Joker", and some online communities have taken him as their mascot (Buckles et al., 2014). According to Manuoğlu (2020), trolling is usually associated with playfulness and a sense of mischief, with some reporting feeling positively about being trolled. However, individuals often categorize their experiences with trolls as negative, and the playful aspect is found to quickly fall away when the trolls harbor negative feelings towards their victims (Manuoğlu, 2020). Positive predictors of trolling were found to be Machiavellianism, psychopathy and overt aggression (Manuoğlu, 2020).

Participants in trolling actively prey upon earnest respondents when discussing controversial issues in order to embarrass them or make them have strong negative emotional responses (Buckles et al., 2014). Motivations for trolling have been found to be social in nature, with those who have been the victim of trolling trying to troll others in an effort to regain selfesteem; internal, purely for enjoyment; or less often circumstantial in nature being purely opportunistic when annoyed by another in online interactions (Cook, Schaafsma, \& Antheunis, 
2018). Trolling is reported to fill desires for personal enjoyment, revenge, and thrill seeking behavior (Cook, Schaafsma, \& Antheunis, 2018).

Beyond personal motivations for trolling, political agendas have been identified as an impetus for the behavior. Flores-Saviaga, Keegan, and Savage (2018) noted that in political contexts there is a motivation to extend political beliefs through the utilization of trolling behavior, and the coopting of trolling symbolism, in order to trigger opponents as well as reinforce the views of others who hold similar beliefs (Flores-Saviaga, Keegan, \& Savage, 2018). State sponsorship of trolling has been noted as a method to intimidate, discredit, humiliate, and frustrate political opposition (Kargar \& Rauchfleish, 2019).

The phenomenon has been positively correlated with all of the dark tetrad traits in a Japanese sample, with Machiavellianism and sadism being the highest (Masui, 2019). Loneliness was found to be a moderating variable regarding Machiavellianism and psychopathy in the Japanese study (Masui, 2019). A study of mostly Australian subjects found that trait psychopathy and trait sadism were positively correlated with trolling behavior (Sest \& March, 2017). The thrill-seeking aspect of psychopathy and the enjoyment found in causing harm to others as possible explanations for these correlations (Sest \& March, 2017).

Klempka and Stimson (2014) reported that trolls can be viewed as a distinct online subculture. Trolls have their own distinct practices and desires, as well as the creation of communities devoted to them, forming the basis for this categorization (Klempka \& Stimson, 2014). Trolling as a practice has greater acceptance among younger internet users rather than those over the age of 35 , however there are limits to the extent of trolling behaviors that are seen as acceptable across all ages, and ones that are seen as universally abhorrent outside of the subculture (Klempka \& Stimson, 2014). 


\subsection{Online Political Discussion}

Early in the history of the internet it was hoped that a new golden age for the marketplace of political ideas would arise, with rational actors undertaking discourse in a way that furthered mutual understanding and created a free exchange of ideas (Wojcieszak \& Mutz, 2009). These idealistic dreams of active intergroup political communication in ways that were less antagonistic and more devoted to understanding did not prove true. However, what has been observed is that political discussion is now commonplace in settings where it is not the main topic of conversation such as discussions of hobbies, professional forums, and sports fandoms (Wojcieszak \& Mutz, 2009). While the majority of political discussion still takes place in settings dedicated to it, through the internet it has proliferated to all facets of life (Wojcieszak \& Mutz, 2009).

The extent to which online political discussion exposes one to differing opinions, or serves to reinforce one's existing opinions applies to this proliferation directly. Forums focusing on topics other than politics directly, such as fandoms, support, or social life, were found to have a greater percentage of differing opinions (Wojcieszak \& Mutz, 2009). Only forums dedicated to ethnicity and religion were found to be more politically homogenous than political forums directly (Wojcieszak \& Mutz, 2009). Echo chambers, where one participates only in groups of like-minded individuals, were found to be overestimated in their existence, with most internet users being exposed to opinions that were not their own and participating in political discourse with those of differing opinions (Stewart, Arif, \& Starbird, 2018; Wojcieszak \& Mutz, 2009).

Contact hypothesis, and intergroup contact theory would hold that these interactions, especially in light of their occurring on forums dedicated to things like mutual support, would lead to greater intergroup understanding and lessened polarization (Allport, Clark, \& Pettigrew, 
1954, Pettigrew, 1998). However, the opposite has been observed (Boxell, 2018). Trends have shown increasing levels of polarization, with an increase of $35 \%$ of the polarization index between 1984 and 2016 (Boxell, 2018). Less than 3\% of Democrats are more conservative than the average Republican, down from $17 \%$ in 1994; less than $1 \%$ of Republicans are more liberal than the average Democrat, down from 23\% in 1994 (Boxell, 2018). Demographic changes in age and education level can account for up to $59 \%$ of this shift, and predict that these trends will continue well into the future, leaving the issue of increasingly antagonistic online political discussion. (Boxell, 2018).

The influence of other geopolitical factors can help further explain the increasing polarization found in online political discussion. State influence by the Russian Federation in online political discussion was first detected in 2014 during the Russian annexation of Crimea from Ukraine (Haigh, Haigh, \& Kozak, 2017). The misinformation campaign sought to provide political cover for the Russian annexation by spreading rumors as fact that Crimea had fallen to literal Nazis backed by the United States Central Intelligence Agency (Haigh, Haigh, \& Kozak, 2017). These false rumors included allegations of multiple atrocities committed by the CIAbacked Nazis, and called for Russian protection to be extended over the peninsula (Haigh, Haigh, \& Kozak, 2017). This misinformation campaign was launched as part of an asymmetrical warfare campaign launched by the Russian Federation against Ukraine, allowing the Russians to take control of Crimea, and leading to continuing warfare in Eastern Ukraine (Haigh, Haigh, \& Kozak, 2017).

Russian influence campaigns in the United States, through their Internet Research Agency (RU-IRA) occurred during the 2016 United States Presidential Election, targeting both Democrats and Republicans for their influence attempts (Stewart, Arif, \& Starbird, 2018). The 
state actors further weaponized the aims of trolling by falsely pretending to be Americans in order to ferment increased polarization within the United States electorate (Stewart, Arif, \& Starbird, 2018). Unlike previous media based propaganda influence campaigns such as Tokyo Rose and Voice of America which acted as direct spokespeople for their side, the RU-IRA campaign sought to blend in fully, become social media influencers and relied heavily upon actual Americans to share their propaganda (Stewart, Arif, \& Starbird, 2018). The RU-IRA utilized existing hashtags, such as \#blacklivesmatter, \#imwithher, and \#feelthebern when targeting the left, and \#trum2016, \#maga, and \#trumptrain when targeting the right in order to integrate into social media conversations that were already taking place (Stewart, Arif, \& Starbird, 2018). The campaign was exceptionally successful in appealing directly to their respective bases, furthering polarization (Stewart, Arif, \& Starbird, 2018). Distinct directed clusters formed for sharing their propaganda, with very little overlap, despite the individuals sharing interacting regularly in antagonistic ways with people from the other side (Stewart, Arif \& Starbird, 2018).

The RU-IRA utilized several standardized tactics during their campaign to influence the 2016 United States presidential election that set them apart from domestic trolls in online political discussion (Zannettou, et al., 2019). RU-IRA trolls would regularly scrub their profiles and start over, in an attempt to delete their digital footprints in a process referred to as "resetting" even when they were not discovered by other users (Zannettou, et al., 2019). They would comment and post regarding specific incidents or ideas in an effort to shape the discussion, while leaving other topics alone if they were not key to their geopolitical agenda or if they had not formed talking points regarding them (Zannettou, et al., 2019). Their activity was almost exclusively from the web client, versus apps on devices, and they zeroed in on specific 
geographic locations, which they wished to influence.. Their efforts were not entirely effective though, as their attempts to inject created misinformation news stories, and to share sensationalist conspiracy theory sources such as InfoWars, did not meet with as much success as their sharing of established sources, even when those were known Russian governmental propaganda entities such as RT (Zannettou, et. al., 2019).

Advances in machine learning and streamlining of the misinformation sharing processes in online political discussion have been noted in the coordinated campaigns to influence online political discussion taking place during the COVID-19 pandemic. While the 2016 campaign by the RU-IRA utilized large numbers of real humans acting as trolls, 2020 has seen a prevalence of bots in the spreading of misinformation (Yang, Torres-Lugo, \& Menczer, 2020). The bot networks have begun spreading misinformation at accelerated rates throughout the pandemic, following a similar path in creation of accounts to what the RU-IRA utilized for their human troll accounts in 2016 (Yang, Torres-Lugo, \& Menczer, 2020, Zannettou, et al., 2019). These bots sought similar goals of furthering polarization, in this case by sharing alarming but legitimate medical information targeted at the American left; and blatant misinterpretation or outright misinformation, both of an inflammatory nature targeted at the American right (Zannettou, et al., 2020). Word cloud analysis of the misinformation being spread by the bots shows that the direction has changed away from created misinformation news sites created in support of the RU-IRA 2016 campaign, or conspiracy theory sites that are discredited to the general public, instead the major source cited is WorldNetDaily (WND), a far-right wing opinion publication that has been in existence since 1997 (Zannettou, et al., 2020). As it stood in late May of 2020, half of all tweets regarding COVID-19, including $82 \%$ of the top 50 influencers, and $62 \%$ of the top 1000 influencers were misinformation bots (Carley, et al., 2020). While the strategies utilized 
are highly indicative of those of the RU-IRA in 2016, resources are not yet available to researchers to conclude who is behind the campaign in 2020 as of this writing (Carley, et al., 2020).

Central to the campaigns waged to influence online political discussion is the utilization of real Americans to propagate their misinformation, and it is fodder for domestic trolls (Ferrara, 2020). As a virus itself needs a host in order to reproduce, state-sponsored influence campaigns need persons in the country they wish to effect to spread their claims (Shao, et al., 2018). Since the misinformation bot network has not yet utilized advanced artificial intelligence to the point where it can leave its given social media platforms to our knowledge, and human propaganda resources are unlikely to risk exposure in order to be studied, a window is open in order to study the host, allowing us to combat these campaigns more effectively in the future.

\section{Hypotheses and Research Questions}

The importance of studying online political discourse in this unique period of American history is paramount not only for understanding current phenomenon, but it is hoped, also for predicting future interactions and creating a record for which our time can be studied by future researchers.

In light of previous research regarding trolling with the Dark Tetrad and communal ingroup based antisocial behavior, it would be expected to find positive correlations between three of the four traits, as well as social dominance orientation with online political trolling (ArtetaGarcia, 2015, Buckles, Trapnell, Andjelovic, \& Paulhas, 2017). As online political trolling is being operationalized as antisocial behavior the following hypothesis was offered:

H1: A positive correlation exists between trait Machiavellianism, trait psychopathy, trait sadism, and social dominance orientation with online political trolling. 
With regards to the relationship between the Dark Triad, and social dominance orientation, it is logical to assume that a similar relationship exists to trait sadism, especially with the research suggesting that trait sadism is predictive of the Triad traits, forming the Dark Tetrad (Buckles, et al., 2013). Therefore, the following hypothesis was offered:

H2: A positive correlation exists between trait Machiavellianism, trait psychopathy, and trait sadism with social dominance orientation.

Narcissism presents interestingly within the Dark traits, and exploring it more here will be helpful to the understanding of the trait, as well as how it relates to outcomes, as such the following research questionwas offered:

RQ1: What relationship exists between narcissism and online political trolling?

In order to evaluate the explanatory and predictive powers of using the traits to understand online political trolling, the following research question was offered:

RQ2: To what extent does the Dark Tetrad and Social Dominance Orientation explain political trolling?

\section{Methods}

\subsection{Participants}

The study sample was collected using an online questionnaire, with inclusion criteria being an American 18 or older, and self-reporting being active in online political discussion. Participants were recruited through the social media websites Facebook and Reddit directly, with Chan pages having possible indirect recruitment through an anonymous link to Qualtrics. Participants consisted of 190 American adults ( 90 female, 82 male, 7 nonbiary, 4 transgender female, 1 transgender male, and 6 listing their gender as "other" with 1 listing as "two-spirit", 1 as "genderfluid", 1 using the Chan meme of "attack helicopter", and 3 participants who used the 
space provided to state derogatory comments towards women and the trans communities).

Participant age ranged from 18 to a claimed age of $344($ median $=32$, mode $=19)$. Participant ethnicity consisted of 157 White/Caucasian, 7 Hispanic/Latino, 7 Asian/Pacific Islander, 4 Native American, 1 Middle Eastern, and 14 listing other (8 mixed ethnicity, 1 Métis, 1 Jewish, 2 responses indicating White supremacist views, and 1 general other). Household income was reported as 30 participants at less than $\$ 25,000,41$ participants at $\$ 25,000-\$ 50,000,58$ participants at $\$ 50,000-\$ 100,000,50$ participants at $\$ 100,000-\$ 250,000$, and 8 participants at greater than $\$ 250,000$. The highest education level of participants was found to be 4 some high school, 27 high school degree, 55 some college, 63 bachelor degree, 37 graduate degree, and 4 with trade degrees. Political party affiliation of participants was reported as 84 Democrats, 25 Libertarians, 12 Republicans, 11 Greens, 15 none/independent, and 43 stated as other (10 Socialists, 5 Communists, 4 Nazis, 3 Centrists, 2 Constitutionalists, 2 Alt-Right, 2 Technocrats, 1 Anarchist, and the rest giving longer explanations of their personal political beliefs without stating party).

\subsection{Procedures}

This study was approved by the Institutional Review Board of the researcher's university prior to the start of recruitment. Recruitment conducted through the summer of 2020 began with the posting on subreddits that were identified to have the highest levels of potential participants of multiple political worldviews through the utilization of software to graphically analyze subscriptions and their networks. A selection of 30 subreddits were identified for recruitment. When contacted, moderators allowed for posting on 24 of those boards. Generalist groups, where individuals may come into contact with the widest possible interaction between members of different ideology were given priority, such as r/politicalcompass, r/politicalhumor and 
r/inthenews. Postings to groups that had large membership, but were focused upon a singular ideology were approved only in r/YangGang, supporters of former Democratic presidential candidate Andrew Yang; r/Libertarian, a libertarian group; three groups supporting centrism, one supporting neoliberalism and one supporting neoconservativism. Efforts were made to recruit from the far left and far right through posting to groups where the two were found to consistently debate each other in r/unpopularopinion, and r/iamverysmart.

After the launch of recruitment, Reddit purged groups that they considered the political fringe, leading to a slowdown in responses. Facebook was identified as a second source of potential recruitment and the recruitment copy was modified only to replace mentions of Reddit with general social media wording.

Facebook recruiting was conducted similarly to Reddit, with the call for participants placed on major multipartisan political discussion groups (a total of 10 Facebook groups). Facebook also allows sharing of posts to other groups and personal pages by members, and a total of 44 shares occurred, with privacy settings preventing viewing of where the original recruitment script was shared.

At some point the Facebook ad copy was captured in a screen shot, along with the link to the study and shared by a third party to various Chan websites. Due to the way that Chan architecture works, posts disappear unless interacted with as new posts are made. As such it is impossible to gauge the full extent to which the ad was shared, even if all Chans could be catalogued, but it was noted to be present on the /pol/ boards of 4Chan and $8 \mathrm{Chan}$. These are political discussion boards frequented by the far-right of American politics, and Chan culture on the whole is highly accepting of trolling (Knuttila, 2011). 
Reddit utilizes screen names that are socially encouraged to be different from one's real name in order to provide a degree of anonymity, unlike other platforms that are more closely tied to one's person such as Facebook. The Chan boards that the study was found to be shared to do not require membership and use default anonymity for all posts and responses. The sharing of study ad copy to discussion focused social media platforms allows for a greater protection from the bot issue that is found on Twitter while greatly increasing the opportunity for quality data.

\subsection{Measures}

Machiavellianism, narcissism, and psychopathy were measured using the Short Dark Triad (SDT) (Jones \& Paullhus, 2014). The SDT-3.1.1 is the most current version of the scale. The traits are measured with nine items each on a 5-point Likert scale, with responses ranging from 1 (Strongly Disagree) to 5 (Strongly Agree). Participants were asked to rate their agreement or disagreement with a series of statements about themselves, with sample questions such as "I like to use clever manipulation to get my way" (Machiavellianism), "I know that I am special because everyone keeps telling me so" (narcissism), and "People often say I'm out of control" (psychopathy). The mean for the Machiavellianism subscale was 3.075, $(S D=0.659)$, the narcissism subscale mean was $2.621(S D=0.643)$, and the psychopathy scale mean was 2.322 $(S D=0.7)$. The coefficient alphas for the subscales were Machiavellianism .762, narcissism .764 , and psychopathy .815 , respectively.

Trait everyday sadism was measured using the Short Sadistic Impulse Scale (SSIS) (O’Meara, Davies, \& Hammond, 2011). The measure includes ten items where participants are asked to rate their agreement or disagreement with a statement about themselves on a 5-point Likert scale from 1 (Strongly Disagree) to 5 (Strongly Agree). Sample items include "I have hurt 
people for my own enjoyment", and "I enjoy seeing people hurt". The mean for the SSIS was $1.834(S D=0.831)$. The coefficient alpha for the SSIS was .912 .

Social dominance orientation was measured using the Social Dominance Orientation-7 (SDO7); Ho, et al.’s (2015) revision of Pratto et al.'s (1994) original measure. Participants are asked to rate their agreement with 8 items on a 5-point Likert scale from 1 (Strongly Disagree) to 5 (Strongly Agree). The scale is evenly split between positively and negatively encoded items, with an example of "Some groups of people are simply inferior to other groups" for positively encoded, and "Groups at the bottom are just as deserving as groups at the top" for negatively encoded. The mean for SDO7 was $2.048(S D=0.975)$. The coefficient alpha for the SDO7 was .920 .

Online trolling behavior was measured by the Global Assessment of Internet Trolling Revised (GAIT-R), which is a revision by Sest and March (2017) of the original GAIT measure (Buckles, Trapnell, \& Paulhus, 2014). Participants are asked to state their agreement or disagreement with 8 statements on a 5-point Likert scale from 1 (Strongly Disagree) to 5 (Strongly Agree). The questions relate to both behavior (e.g., "I have sent people to shock websites for the lulz") and beliefs (e.g. "The more beautiful and pure a thing is, the more satisfying it is to spoil"). The mean for GAIT-R was $2.180(S D=0.887)$. The coefficient alpha was .864 .

\section{Results}

H1 predicted that positive correlations existed between trait Machiavellianism, trait psychopathy, trait sadism, and social dominance orientation with online political trolling. This hypothesis was supported. Zero order correlations were examined (table 1) finding that all traits correlated positively with trolling in statistically significant relationships across all relationships 
$(\mathrm{p}<0.001)$. Machiavellianism correlated positively at 0.557 , trait psychopathy positively at 0.651 , trait sadism positively at 0.617 , and SDO positively at 0.555 .

$\mathrm{H} 2$ predicted that a positive correlation exists between trait Machiavellianism, trait psychopathy, and trait sadism with social dominance orientation. This hypothesis was fully supported. Zero order correlations (table 1), found statistically significant positive correlations ( $\mathrm{p}$ $<0.001)$ between Machiavellianism and SDO (0.481), trait psychopathy and SDO (0.408), as well as trait sadism and SDO (0.507).

RQ1 investigated the relationship between trait narcissism and political trolling. A zero order regression (table 1$)$ did find a statistically significant $(\mathrm{p}<0.001)$ positive relationship between narcissism and trolling (0.432).

RQ2 asked to what extent does the Dark Tetrad and Social Dominance Orientation explain political trolling. The results of the multiple regression analysis indicate that the combination of Machiavellianism, trait psychopathy, and SDO account for $55.9 \%$ of variance (table 2).

Table 1:

\begin{tabular}{|c|c|c|c|c|c|}
\hline & Machiavellianism & Narcissism & Psychopathy & Sadism & $\begin{array}{l}\text { Social } \\
\text { Dominance } \\
\text { Orientation }\end{array}$ \\
\hline Machiavellianism & - & & & & \\
\hline Narcissism & $0.330 *$ & - & & & \\
\hline Psychopathy & $0.570 *$ & $0.487 *$ & - & & \\
\hline Sadism & $0.585^{*}$ & $0.420 *$ & $0.700 *$ & - & \\
\hline $\mathrm{SDO}$ & $0.481 *$ & $0.258^{*}$ & $0.408 *$ & $0.507^{*}$ & - \\
\hline Trolling & $0.557 *$ & $0.432 *$ & $0.651 *$ & $0.617 *$ & $0.555^{*}$ \\
\hline
\end{tabular}

Note: $* p<0.001$ 
Table 2.1:

\begin{tabular}{|l|l|r|l|}
\hline \multicolumn{4}{|c|}{ Variables Entered/Removed $^{\mathrm{a}}$} \\
\hline Model & Variables Entered & $\begin{array}{l}\text { Variables } \\
\text { Removed }\end{array}$ & Method \\
\hline 1 & $\begin{array}{l}\text { Machiavellianism, } \\
\text { Narcissism, } \\
\end{array}$ & None & Enter \\
& $\begin{array}{l}\text { Psychopathy, } \\
\text { Sadism, } \\
\text { SDO }^{\mathrm{b}}\end{array}$ & & \\
& & & \\
\hline
\end{tabular}

a. Dependent Variable: Trolling

b. All requested variables entered.

Table 2.2:

\begin{tabular}{|l|c|c|c|c|}
\hline \multicolumn{5}{|c|}{ Model Summary } \\
\hline Model & $\mathrm{R}$ & R Square & $\begin{array}{c}\text { Adjusted R } \\
\text { Square }\end{array}$ & $\begin{array}{c}\text { Std. Error of } \\
\text { the Estimate }\end{array}$ \\
\hline 1 & $.748^{\mathrm{a}}$ & .559 & .547 & .59670 \\
\hline \multicolumn{4}{|c|}{$\begin{array}{l}\text { a. Predictors: (Constant), Machiavellianism, narcissism psychopathy, } \\
\text { sadism, SDO }\end{array}$} \\
\hline
\end{tabular}

Table 2.3:

\begin{tabular}{|c|c|c|c|c|c|c|}
\hline \multicolumn{7}{|c|}{ ANOVA $^{\mathrm{a}}$} \\
\hline \multicolumn{2}{|c|}{ Model } & $\begin{array}{l}\text { Sum of } \\
\text { Squares }\end{array}$ & df & Mean Square & $\mathrm{F}$ & Sig. \\
\hline \multirow[t]{3}{*}{1} & Regression & 83.029 & 5 & 16.606 & 46.638 & $.000^{\mathrm{b}}$ \\
\hline & Residual & 65.514 & 184 & .356 & & \\
\hline & Total & 148.543 & 189 & & & \\
\hline \multicolumn{7}{|c|}{ a. Dependent Variable: Trolling } \\
\hline \multicolumn{7}{|c|}{ b. Predictors: (Constant), Machiavellianism, narcissism, psychopathy, sadism, SDO } \\
\hline
\end{tabular}


Table 2.4:

\begin{tabular}{|c|c|c|c|c|c|c|c|c|}
\hline \multicolumn{9}{|c|}{ Coefficients $^{\mathrm{a}}$} \\
\hline \multirow{2}{*}{\multicolumn{2}{|c|}{ Model }} & \multicolumn{2}{|c|}{$\begin{array}{l}\text { Unstandardized } \\
\text { Coefficients }\end{array}$} & \multirow{2}{*}{$\begin{array}{c}\text { Standardize } \\
\text { d } \\
\text { Coefficients } \\
\text { Beta }\end{array}$} & \multirow[t]{2}{*}{$\mathrm{t}$} & \multirow[t]{2}{*}{ Sig. } & \multicolumn{2}{|c|}{$\begin{array}{c}95.0 \% \text { Confidence } \\
\text { Interval for B }\end{array}$} \\
\hline & & $\mathrm{B}$ & $\begin{array}{l}\text { Std. } \\
\text { Error }\end{array}$ & & & & $\begin{array}{l}\text { Lower } \\
\text { Bound } \\
\end{array}$ & $\begin{array}{l}\text { Upper } \\
\text { Bound }\end{array}$ \\
\hline \multirow[t]{6}{*}{1} & (Constant) & -.415 & .247 & & -1.679 & .095 & -.902 & .073 \\
\hline & Machiavellianism & .177 & .087 & .132 & 2.027 & .044 & .005 & .349 \\
\hline & Narcissism & .147 & .078 & .107 & 1.888 & .061 & -.007 & .301 \\
\hline & Psych & .404 & .094 & .319 & 4.290 & .000 & .218 & .589 \\
\hline & Sadism & .148 & .080 & .138 & 1.836 & .068 & -.011 & .306 \\
\hline & $\mathrm{SDO}$ & .240 & .054 & .264 & 4.488 & .000 & .135 & .346 \\
\hline
\end{tabular}

a. Dependent Variable: Trolling

\section{Discussion}

A common theme to previous studies in trolling behavior has been the call for greater research. While trait psychological research into trolling so far has studied the relationships between the Dark Tetrad and the behavior, the intention of this study was to replicate these efforts and to extend them with the inclusion of SDO in a sample of social media users active in political discussion in the United States.

While H1 was fully supported when looking at zero order correlations, the regression analysis conducted for RQ2 (table 2$), F(5,184)=46.638, \mathrm{p}<0.001, R^{\wedge} 2=0.559$, found that SDO $(p<0.001$, std. beta $=0.264)$ psychopathy $(p<0.001$, std. beta $=0.319)$, and Machiavellianism $(\mathrm{p}=0.44$, std. beta $=0.132)$ were the only statistically significant predictors $(\mathrm{p}$ $<0.05)$ of trolling behavior.

The findings of this study closely match those of Masui (2019). Both found significant zero order positive correlations between the Dark Tetrad and trolling behavior, and found 
relationships with Machiavellianism and psychopathy in regression analysis (Masui, 2019). The inclusion of loneliness as a moderating variable was beyond the scope of this study, and will be discussed further in future directions. Masui's (2019) sample of Japanese participants randomly selected from a survey database also did not focus upon the political motivations for trolling, nor did it include SDO as a variable, but the GAIT variant used proved valid when tested with the Dark Tetrad in that sample as well.

These results significantly differ from Sest and March (2017), which used the GAIT measure, where trait sadism was found to be positively related to trolling behaviors, along with psychopathy, and cognitive empathy, while affective empathy was found to be negatively related to trolling behaviors. Sest and March's (2017) sample was taken from a multinational survey, where the majority of participants were Australian. Taking into account Boxell's (2018) predictions that political polarization would play an increasing role regarding political discussion in the United States, and given the conditions under which the present study was undertaken during the summer of 2020, a potential explanation could come from the focus of this study being taken from social media groups devoted to political discussion yielding different results from those in a general international population.

Furthermore, Sest and March (2017) inclusion of empathy measures, while the present study included SDO, could provide insight. There is a negative correlation between empathy and SDO within the context of understanding intergroup beliefs (Pratto, et al., 1994). Concern for others as a key component of empathy specifically neutralizes one's desire to dominate other groups (Pratto, et al., 1994). With cognitive empathy being the ability to merely understand the feelings of others, and affective empathy being the ability to internalize that understanding, it is logical that individuals high in SDO do not necessarily lack understanding of others emotions, 
but the factor of concern for others could come from the inability or lack of desire to internalize these feelings (Sest \& March, 2017). The positive relationship found between psychopathy and trolling behavior in both studies is a possible explanation for this, as psychopathy is negatively related to both empathy as well as conscientiousness (Paulhus \& Williams, 2002).

The question of the relationship between narcissism and trolling behavior was raised not only because of its inclusion within the Dark Tetrad, but because of the results of previous studies. This study's findings are in line with the body of work that shows while there are positive zero order correlations between trolling behavior and narcissism, the relationship is not found to be statistically significant when placed into regression analysis. These findings are in line with previous research into the relationship between the dark traits and trolling behavior (Masui, 2019; Sest \& March, 2017). It is possible that the nature of trolling requiring deception regarding the self and intention proves unappealing to those high in narcissism (Hardaker, 2010).

Narcissism is directly tied to identities of the self, and positive perception of the self in the Short Dark Triad, measuring grandiose narcissism (McCain, et al., 2016). While need for recognition has found to be a motive in trolling behavior (Hardaker, 2010), the nature of grandiose narcissism requires that need to be recognized directly for the self, without deception, that goes counter to the positive perception of the self.

In the context of posting selfies, grandiose narcissism was found to have a positive correlation with the behavior and with feelings of positive affirmation at their reception, while vulnerable narcissism, which SDT alone does not account for, found a negative correlation with the behavior (McCain, et al., 2016). It is possible that the positive view of self in the measure can help explain the lack of statistically significant relationship between narcissism and trolling behavior in the regression analysis. 
Social Dominance Orientation's positive relationship to trolling behavior supports previous findings that showed a positive relationship with SDO and dark traits (Hodson, Hogg, \& MacInnis, 2009). With the increasing polarization of the United States political discourse, when studying the relationships between traits and behaviors, it is useful today to pair measures that examine political beliefs along with behaviors in political communication (Boxell, 2018).

The links between the Dark Tetrad, SDO and political views are documented. SDO positively correlates with a variety of right wing political views (Pratto, et al., 1994). In the Dark Tetrad, all of the traits are positively related to right wing extremism (Duspara \& Greitemeyer, 2017). The present study includes a higher percentage of participants from extreme right wing political viewpoints than previous work looking at political trolling, possibly due to the study being shared to Chan websites through Facebook. The presence of self-identifying participants of Alt-Right, and Nazi political affiliations is novel, and serves to provide insight into an understudied group that is known for engaging in political trolling activity (Knuttila, 2011).

The sample of self-identified right wing extremists is too small to make statistically significant observations that would be generalizable, but the use of a Chan meme for gender is notable, as is inclusion of a particularly long explanation of one participant's political views that was placed in the included small text box for other in the political affiliation demographics question (see appendix E). Responses such as these raise questions regarding the decision making process regarding trolling behavior: is there a deliberative process before undertaking the behavior for all, or are attempts at trolling sometimes pathological in nature?

The positive correlation between psychopathy and trolling behavior could imply that there is an impulsive component to trolling behavior. The socially desirable nature of trolling behavior in Chan communities, along with research indicating the relationship between need for 
recognition present in trolling behavior, could elicit an impulsive response in those high in psychopathy as a possible explanation for trolling as an impulsive behavior (Hardaker, 2010; Knuttila, 2011; Manuoğlu, 2020).

While state sponsored political trolling is well beyond the scope of this study, the relationship between SDO and Dark Triad traits related to right wing political views, and trolling behavior present possible rationales for why domestic non-affiliated individuals may cooperate with foreign government sponsored trolling methodologies. The methodology of this study was designed in such a way as to preclude as much as possible pollution of the data by government trolling bot networks through sampling from discussion oriented social media platforms along with requiring a click through link to the survey hosted on a separate website. It would be naïve though to assume that none of the participants had ever been influenced or interacted with state sponsored trolling bots as the sampled social media platforms are open systems regarding message sharing with other platforms.

In attempts to track how the survey link was shared to the Chan sites, organizing groups for the QAnon conspiracy community were discovered as adjacent to those the survey was noted to be present on, and a number of other posts on the pages with the link were related to that conspiracy as well as others that have been noted to be related to state sponsored efforts to sway political opinion in the United States.

Trolling has been conceptualized as an individual behavior undertaken when dealing with a larger group (Hardaker, 2010). However, politically motivated trolling acts on behalf of one political group towards another or to those who are undecided (Flores-Saviaga, Keegan, \& Savage, 2018). The presence of state sponsored influence campaigns in the same digital spaces occupied by domestic political trolls gives foreign governments potentially a ready supply of 
willing actors on their behalf so long as their influence aims are congruous with the troll's beliefs. There was direct evidence of this in documents found on 8Chan showing an intricately planned system of coordinated trolling efforts for the QAnon conspiracy to be utilized on the Twitter platform (see provided example in appendix F).

\subsection{Limitations}

The primary limitations of the current study are related to the sample. A small sample size of 190 participants taken only from residents of the United States that are Reddit and Facebook users should preclude extrapolation of the findings beyond those studied. The inclusion of demographic questions directly after the GAIT measure may have had an unintended priming effect on the demographic data by those high in trolling behavior. For example, one participant put their age as a series of $9 \mathrm{~s}$ and another as 235 , making the mean age of participants in this study meaningless.

Demographic information regarding political affiliation are not representative of the United States, the same is the case for ethnic demographics with the very notable lack of any African American/Black participants. It is possible that the trolling aspect, especially with the potential for inclusion of Chan community participants resulted in bias as well, although no participants who answered with all 1 s or all $5 \mathrm{~s}$ were found.

The scope of this study was intentionally limited to the Dark Tetrad, SDO and trolling behaviors, and as such should not be taken as a complete explanation of all motivations for political trolling behaviors. As was noted, state sponsored political trolling activities were deliberately not examined either. The focus of this study did not include different forms of the examined traits, and should not be taken as a complete examination of all interactions under the traits. 


\subsection{Directions for future research}

The usage of short form measures in the present study presents questions regarding deeper examination of each of the traits along with trolling behavior. The intended time to complete the measures was estimated at 15 minutes, however participant average time to completion was less (9:09 minutes). This suggests that measures covering greater depth, or alternative measures could be used with this methodology without concern regarding participant fatigue.

It is suggested that studies looking into grandiose narcissism and vulnerable narcissism, along with SDO and the rest of the Dark Tetrad be undertaken in order to fully explore the role that narcissism plays. This methodology also lends itself well to testing of the newly created System Justification Beliefs measure against SDO with regards to trolling behavior.

While the GAIT showed to be reliable and valid in the present study, there is still a need to produce a measure for trolling behavior that is valid cross-culturally (Manuoğlu, 2020). A standard methodology can then be developed in a way that allows for analysis of correlations with traits so as to examine variance universally. There are still a great many questions regarding the role of political beliefs in online behavior, and these will only be amplified in cultures with greater levels of polarization as more of our discourse moves into digital spaces.

Compact, tight survey design also allows for utilization when examining multiple behaviors. The current methodology should be modified and expanded not only to provide greater understanding of trolling behaviors but of other politically charged phenomena as well. Utilizing a similar survey design, the GAIT could be replaced with questions regarding attitudes regarding the COVID-19 pandemic, in an extension of the work of Nowak, et al. (2020). 
The current study only could account for $55.9 \%$ of variance regarding trolling behavior. While the amount of interest within the academic community regarding the study of trolling behavior, there is still a great deal of study that needs to be undertaken in order to fully explain this relatively new, and increasingly dangerous, online behavior.

\section{Conclusion}

The Dark Tetrad traits (Machiavellianism, narcissism, psychopathy, and sadism) along with Social Dominance Orientation all positively correlated with each other and with trolling behavior. Regression analysis found that Machiavellianism, psychopathy and social dominance orientation correlate positively with trolling behavior, accounting for $55.9 \%$ of the variance. It is suggested by that measures of political attitudes and politically related traits be included in future studies regarding trolling behavior. 


\section{References}

Allport, G. W., Clark, K., \& Pettigrew, T. (1954). The nature of prejudice. Addison-Wesley. Arteta-Garcia, J. (2015). The mediating role of social dominance orientation between dark tetrad personalities and hazing behaviors in college students (Unpublished masters thesis). Texas State University, San Marcos, TX, United States of America.

Boxell, L. (2020). Demographic change and political polarization in the United States. Economics Letters, pre-proof 109187. doi:10.1016/j.econlet.2020.109187

Buckels, E. E., Jones, D. N., \& Paulhus, D. L. (2013). Behavioral confirmation of everyday sadism. Psychological Science, 24, 2201-2209. doi:10.1177/095679761340749

Buckels, E. E., Trapnell, P. D., Andjelovic, T., \& Paulhus, D. L. (2017). Internet trolling and everyday sadism: Parallel effects on pain perception and moral judgement. Journal of Personality, 87, 328-340. doi:10.1111/jopy.12393

Buckels, E. E., Trapnell, P. D., \& Paulhus, D. L. (2014). Trolls just want to have fun. Personality and Individual Differences, 67, 97-102. doi:10.1016/j.paid.2014.01.016

Cook, C., Schaafsma, J., \& Antheunis, M. (2018). Under the bridge: An in-depth examination of online trolling in the gaming context. New Media \& Society, 20, 3323-3340. doi:10.1177/1461444817748578

Cracker, N., \& March, E. (2016). The dark side of Facebook: The dark tetrad, negative social potency, and trolling behaviours. Personality and Individual Differences, 102, 79-84. doi:10.1016/j.paid.2016.06.043

Ferrara, E. (2020). \# COVID-19 on Twitter: Bots, conspiracies, and social media activism. arXiv preprint arXiv:2004.09531. 
Fichman, P., \& Dainas, A. R. (2019). Graphicons and tactics in satirical trolling on Tumblr.com. International Journal of Communication, 13, 4261-4286.

Flores-Saviaga, C. I., Keegan, B. C., \& Savage, S. (2018, June). Mobilizing the trump train: Understanding collective action in a political trolling community. In Twelfth International AAAI Conference on Web and Social Media.

Goodboy, A. K., \& Martin, M. M. (2015). The personality profiled of a cyberbully: Examining the dark triad. Computers in Human Behavior, 49, 1-4. doi:10.1016/j.chb.2015.02.052

Haigh, M., Haigh, T., \& Kozak, N. I. (2018). Stopping fake news: The work practices of peer-to peer counter propaganda. Journalism Studies, 19, 2062-2087.

doi:10.1080/1461670X.2017.1316681

Hardaker, C. (2010). Trolling in asynchronous computer-mediated communication: From user discussions to academic definitions. Journal of Politeness Research, 6, 215-242. doi:10.1515/jplr.2010.011

Ho, A. K., Sidanius, J., Kteily, N., Sheehy-Skeffington, J., Pratto, F., Henkel, K. E., ... \& Stewart, A. L. (2015). The nature of social dominance orientation: Theorizing and measuring preferences for intergroup inequality using the new $\mathrm{SDO}_{7}$ scale. Journal of Personality and Social Psychology, 109, 1003-1028. doi:10.1037/pspi0000033

Hodson, G., Hogg, S. M., \& MacInnis, C. C. (2009). The role of "dark personalities" (narcissism, Machiavellianism, psychopathy), big five personality factors, and ideology in explaining prejudice. Journal of Research in Personality, 43, 686-690.

doi:10.1016/j.jrp.2009.02.005 
Horan, S. M., Guinn, T. D., \& Banghart, S. (2015). Understanding relationships among the dark triad personality profile and romantic partners' conflict communication. Communication Quarterly, 63, 156-170. doi:10.1080/01463373.2015.1012220

Jonason, P. K. (2014). How "dark" personality traits and perceptions come together to predict racism in Australia. Personality and Individual Differences, 72, 47-51. doi:10.1016/j.paid.2014.08.030

Jonason, P. K., Slomski, S., \& Partyka, J. (2012). The Dark Triad at work: How toxic employees get their way. Personality and Individual Differences, 52, 449-453. doi:10.1016/j.paid.2011.11.008

Jones, D. N., \& Paulhus, D. L. (2014). Introducing the short dark triad (SD3): A brief measure of dark personality traits. Assessment, 21, 28-41. doi:10.1177/1073191113514105

Kargar, S., \& Rauchfleisch, A. (2019). State-aligned trolling in Iran and the double-edged affordances of Instagram. New Media \& Society, 21, 1506-1527. doi:10.1177/1461444818825133

Kircaburun, K., Demetrovics, Z., \& Tosuntas, S. B. (2018). Analyzing the links between problematic social media use, dark triad traits and self-esteem. International Journal of Mental Health and Addiction, 17, 1496-1507. doi:10.1007/s11469-018-9900-1

Klempka, A., \& Stimson, A. (2014). Anonymous communication on the internet and trolling. Concordia Journal of Communication Research, 1, article 2.

Knuttila, L. (2011). User unknown: 4chan, anonymity and contingency. First Monday, 16. doi:10.5210/fm.v16i10.3665 
Manuoğlu, E. (2020). Differences between trolling and cyberbullying and examination of trolling from self-determination theory perspective (Doctoral dissertation, Middle East Technical University). retrieved from: http://etd.lib.metu.edu.tr/upload/12625470/index.pdf

Masui, K. (2019). Loneliness moderates the relationship between dark tetrad personality traits and internet trolling. Personality and Individual Differences, 150, 109475. doi:10.1016/j.paid.2019.06.018

McCain, J. L., Borg, Z. G., Rothenberg, A. H., Churillo, K. M., Weiler, P., \& Campbell, W. K. (2016). Personality and selfies: Narcissism and the Dark Triad. Computers in Human Behavior, 64, 126-133. doi:10.1016/j.chb.2016.06.050

Nowak, B., Brzóska, P., Piotrowski, J., Sedikides, C., Żemojtel-Piotrowska, M., \& Jonason, P. K. (2020). Adaptive and maladaptive behavior during the COVID-19 pandemic: The roles of Dark Triad traits, collective narcissism, and health beliefs. Personality and Individual Differences, 167, 110232. doi:10.1016/j.paid.2020.110232

O’Meara, A., Davies, J., \& Hammond, S. (2011). The psychometric properties and utility of the short sadistic impulse scale (SSIS). Psychological Assessment, 23, 523-531. doi: $10.1037 / \mathrm{a} 0022400$

Paulhus, D. L., \& Williams, K. M. (2002). The dark triad of personality: Narcissism, Machiavellianism, and psychopathy. Journal of Research in Personality, 36, 556-563. doi:10.1016/S0092-6566(02)00505-6

Pettigrew, T. F. (1998). Intergroup contact theory. Annual Review of Psychology, 49, 65-85. doi:10.1146/annurev.psych.49.1.65 
Pratto, F., Liu, J. H., Levin, S., Shih, M., Bachrach, H., \& Hegarty, P. (2000). Social dominance orientation and the legitimization of inequality across cultures. Journal of Cross-Cultural Psychology, 31, 369-409. doi:10.1177/0022022100031003005

Pratto, F., Sidanius, J., Stallworth, L. M., \& Malle, B. F. (1994). Social dominance orientation: A personality variable predicting social and political attitudes. Journal of Personality and Social Psychology, 67, 741-763. doi:10.1037/0022-3514.67.4.741

Rudman, L. A., \& Saud, L. H. (2020). Justifying social inequalities: The role of social Darwinism. Personality and Social Psychology Bulletin, 46, 1139-1155. doi:10.1177/0146167219896924

Sest, N., \& March, E. (2017). Constructing the cyber-troll: Psychopathy, sadism, and empathy. Personality and Individual Differences, 119, 69-72. doi:10.1016/j.paid.2017.06.038

Shao, C., Ciampaglia, G. L., Varol, O., Yang, K. C., Flammini, A., \& Menczer, F. (2018). The spread of low-credibility content by social bots. Nature Communications, 9, 1-9. doi:10.1038/s41467-018-06930-7

Stewart, L. G., Arif, A., \& Starbird, K. (2018, February). Examining trolls and polarization with a retweet network. In Proc. ACM WSDM, workshop on misinformation and misbehavior mining on the web.

Wojcieszak, M. E., \& Mutz, D. C. (2009). Online groups and political discourse: Do online discussion spaces facilitate exposure to political disagreement? Journal of Communication, 59, 40-56. doi:10.1111/j.1460-2466.2008.01403.x

Yang, K. C., Torres-Lugo, C., \& Menczer, F. (2020). Prevalence of low-credibility information on Twitter during the COVID-19 outbreak. arXiv preprint arXiv:2004.14484. 
Zannettou, S., Caulfield, T., De Cristofaro, E., Sirivianos, M., Stringhini, G., \& Blackburn, J. (2019, May). Disinformation warfare: Understanding state-sponsored trolls on Twitter and their influence on the web. In Companion Proceedings of The 2019 World Wide Web Conference (pp. 218-226). doi:10.1145/3308560.3316495 
Appendix A

Short Dark Triad-3.1.1

Please rate your agreement or disagreement with each item using the following guidelines.

\begin{tabular}{|c|c|c|c|c|}
\hline 1 & 2 & 3 & 4 & 5 \\
\hline $\begin{array}{c}\text { Strongly } \\
\text { Disagree }\end{array}$ & Disagree & $\begin{array}{c}\text { Neither Agree } \\
\text { nor Disagree }\end{array}$ & Agree & $\begin{array}{c}\text { Strongly } \\
\text { Agree }\end{array}$ \\
\hline
\end{tabular}

\section{Machiavellianism subscale}

1. It's not wise to tell your secrets.

2. I like to use clever manipulation to get my way.

3. Whatever it takes, you must get the important people on your side.

4. Avoid direct conflict with others because they may be useful in the future.

5. It's wise to keep track of information that you can use against people later.

6. You should wait for the right time to get back at people.

7. There are things you should hide from other people because they don't need to know.

8. Make sure your plans benefit you, not others.

9. Most people can be manipulated.

\section{Narcissism subscale}

1. People see me as a natural leader.

2. I hate being the center of attention. (R)

3. Many group activities tend to be dull without me.

4. I know that I am special because everyone keeps telling me so.

5. I like to get acquainted with important people.

6. I feel embarrassed if someone compliments me. (R)

7. I have been compared to famous people.

8. I am an average person. (R)

9. I insist on getting the respect I deserve. 


\section{Psychopathy}

1. I like to get revenge on authorities.

2. I avoid dangerous situations. (R)

3. Payback needs to be quick and nasty.

4. People often say I'm out of control.

5. It's true that I can be mean to others.

6. People who mess with me always regret it.

7. I have never gotten into trouble with the law. (R)

8. I enjoy having sex with people I hardly know

9. I'll say anything to get what I want. 


\section{Appendix B}

\section{Short Sadistic Impulse Scale}

Please rate your agreement or disagreement with each item using the following guidelines.

\begin{tabular}{|c|c|c|c|c|}
\hline 1 & 2 & 3 & 4 & 5 \\
\hline $\begin{array}{c}\text { Strongly } \\
\text { Disagree }\end{array}$ & Disagree & $\begin{array}{c}\text { Neither Agree } \\
\text { nor Disagree }\end{array}$ & Agree & $\begin{array}{c}\text { Strongly } \\
\text { Agree }\end{array}$ \\
\hline
\end{tabular}

1. People would enjoy hurting others if they gave it a go.

2. Hurting people would be exciting.

3. I have hurt people because I could.

4. I wouldn't intentionally hurt anyone. (R)

5. I have hurt people for my own enjoyment.

6. I have humiliated others to keep them in line.

7. I would enjoy hurting someone physically, sexually, or emotionally.

8. I enjoy seeing people hurt.

9. I have fantasies which involve hurting people.

10. Sometimes I get so angry I want to hurt people. 


\section{Appendix C \\ Social Dominance Orientation-7}

Please rate your agreement or disagreement with each item using the following guidelines.

\begin{tabular}{|c|c|c|c|c|}
\hline 1 & 2 & 3 & 4 & 5 \\
\hline $\begin{array}{l}\text { Strongly } \\
\text { Disagree }\end{array}$ & Disagree & $\begin{array}{c}\text { Neither Agree } \\
\text { nor Disagree }\end{array}$ & Agree & $\begin{array}{c}\text { Strongly } \\
\text { Agree }\end{array}$ \\
\hline
\end{tabular}

\section{Protrait dominance:}

1. An ideal society requires some groups to be on top and others to be on the bottom.

2. Some groups of people are simply inferior to other groups.

\section{Contrait dominance:}

1. No one group should dominate in society. (R)

2. Groups at the bottom are just as deserving as groups at the top. (R)

\section{Protrait anti-egalitarianism}

1. Group equality should not be our primary goal.

2. It is unjust to try to make groups equal.

\section{Contrait anti-egalitarianism}

1. We should do what we can to equalize conditions for different groups. (R)

2. We should work to give all groups an equal chance to succeed. (R) 


\section{Appendix D}

\section{Global Assessment of Internet Trolling-Revised}

Please rate your agreement or disagreement with each item using the following guidelines.

\begin{tabular}{|c|c|c|c|c|}
\hline 1 & 2 & 3 & 4 & 5 \\
\hline $\begin{array}{c}\text { Strongly } \\
\text { Disagree }\end{array}$ & Disagree & $\begin{array}{c}\text { Neither Agree } \\
\text { nor Disagree }\end{array}$ & Agree & $\begin{array}{c}\text { Strongly } \\
\text { Agree }\end{array}$ \\
\hline
\end{tabular}

1. I have disrupted people in comment sections of websites.

2. I have shared or sent disturbing or controversial material on the Internet for the lulz.

3. I enjoy upsetting people I do not personally know on the Internet.

4. Although some people think my posts/comments are offensive, I think they are funny.

5. I say what I like, and if people can't handle it it's just because they can't handle the truth.

6. I prefer not to cause controversy or stir up trouble (R)

7. The more beautiful and pure a thing is, the more satisfying it is to spoil.

8. I have sent people to shock websites for the lulz.

\section{Appendix E}

\section{Notable political affiliation opinion of participant}

“Ethnonationalism for all races (genetically separate species). Only one ethnicity per nation. Interest on loans/payments $=$ death penalty. Social traditionalism (pre-Victorian) in all things. Child abuse in any form = death penalty. What political party is that? Because they're all fucking communists today. Ever read the communist manifesto? They all support it." 


\section{Appendix F}

Flowchart for trolling and dissemination of information on Twitter by QAnon conspiracy

believers on 8Chan
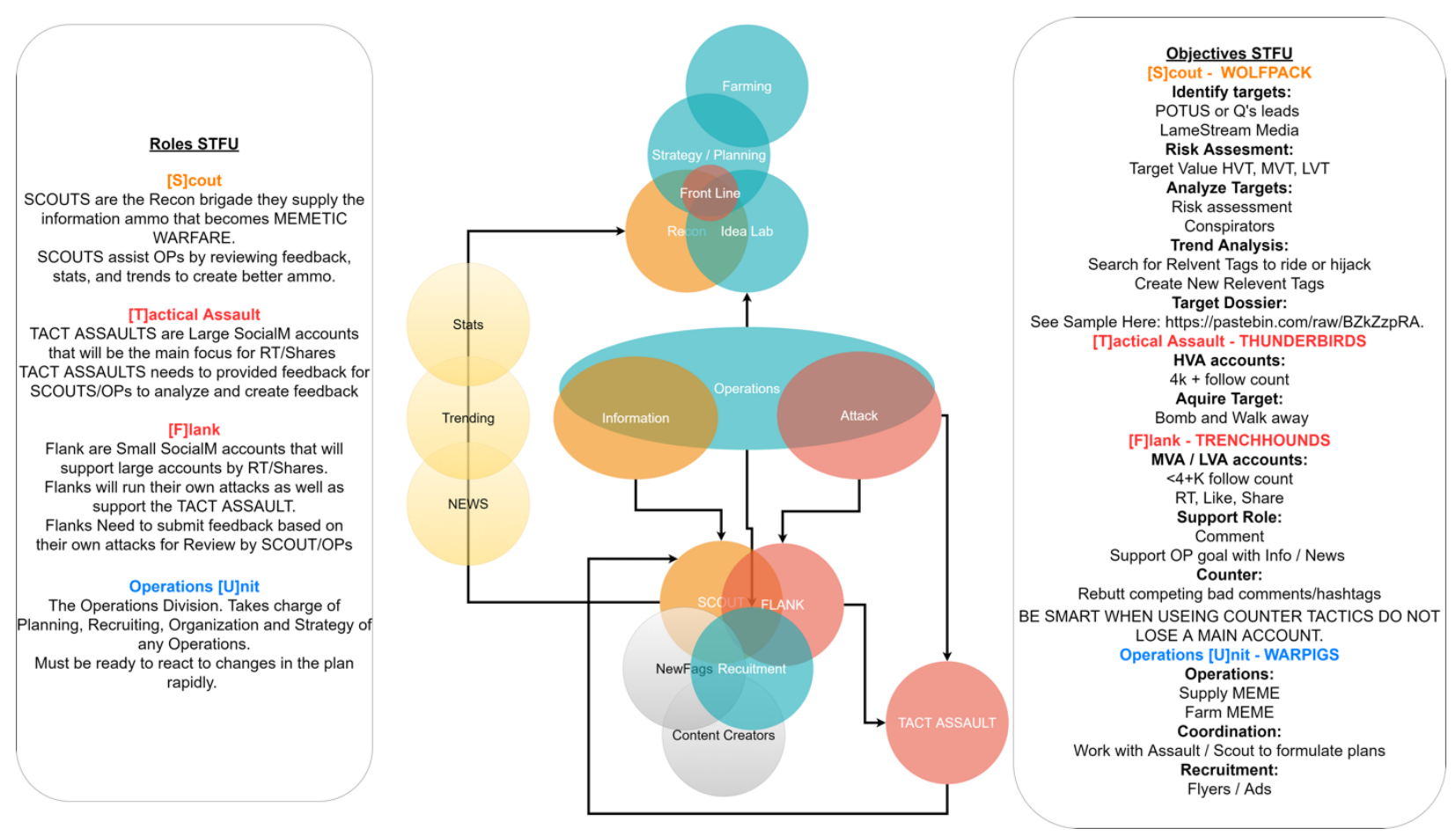